\title{
Vertical Stratification of Microbial Communities in Woody Plants
}

\author{
Mohammad Bahram, ${ }^{1,2, \dagger}$ Kati Küngas, ${ }^{1, \dagger}$ Mari Pent, ${ }^{1,3}$ Sergei Põlme, ${ }^{1,3}$ Daniyal Gohar, ${ }^{1}$ and Kadri Põldmaa ${ }^{1,3}$ \\ ${ }^{1}$ Department of Botany, Institute of Ecology and Earth Sciences, University of Tartu, 40 Lai St, Tartu, Estonia \\ ${ }^{2}$ Department of Ecology, Swedish University of Agricultural Sciences, Ulls väg 16, 75651 Uppsala, Sweden \\ ${ }^{3}$ Natural History Museum and Botanical Garden, University of Tartu, Vanemuise 46, Tartu 51003, Estonia
}

Accepted for publication 18 October 2021.

\begin{abstract}
Bacterial and fungal endophytes form diverse communities and contribute to the performance and health of their host plants. Recent evidence suggests that both host-related factors and environmental conditions determine the community structure of plant endophytes. However, we know little about their distribution patterns and underlying community assembly mechanisms across plant compartments. Here, we analyzed the structure of bacterial and fungal communities associated with tree compartments as well as their underlying soils across 12 tree individuals in boreal forests. We found that the structure of bacterial and fungal communities depends more strongly on the vertical location of tree compartments rather than the locality, species, and individuals of host trees. Microbial communities showed much stronger host specificity in aboveground than

belowground compartments. Compared with fungal communities, the composition and diversity of bacterial communities were markedly more distinct between below- and aboveground components but not between hosts, reflecting the greater importance of environmental conditions rather than dispersal limitation and host identity in their community assembly. Our data suggest that spatial distance from soil as a major microbiome source contributes to the formation of microbiomes in plants, and that bacterial and fungal communities may follow contrasting assembly processes in associating with a single individual tree.

Keywords: ecology, metabarcoding, microbial diversity, microbiome, microorganism, nestedness, plant-soil interactions, symbiosis
\end{abstract}

Plants form diverse communities of microbes in their tissues and organs (Bulgarelli et al. 2012; Lundberg et al. 2012). Such microbes play a key role in nutrient uptake and health of woody plants as mutualists and pathogens (Bulgarelli et al. 2012; Tedersoo et al. 2020). In addition, a diverse group of microbes associate with plants as endophytes. However, we know little about how their communities are formed inside plant tissues and organs. Understanding the

${ }^{\dagger}$ Corresponding authors: M. Bahram; bahram@ut.ee, and K. Küngas; kati.kungas@ut.ee

Author contributions: M.B., K.K., and K.P. conceived the project and wrote the manuscript. K.K., K.P., and S.P. collected the samples. M.B., K.K., D.G., S.P., and M.P. analyzed the data. All authors contributed to manuscript revision and approval of the submitted manuscript.

Funding: Funding was provided by the Estonian Ministry of Education and Research (Eesti Teadusagentuur, grant number PRG1170) and the European Union through the European Regional Development Fund (the Center of Excellence: EcolChange) and Swedish Research Council (Vetenskapsrådet, grant number 2017-05019).

*The $e$-Xtra logo stands for "electronic extra" and indicates that five supplementary figures and eight supplementary tables are published online.

The author(s) declare no conflict of interest.

(C) 2022 The American Phytopathological Society mechanisms shaping the community structure of microbes across compartments of plants, which together form the "holobiont", can inform us about their potential roles as well as how these may alter with environmental changes. This can improve efforts against the decline of woody plants, given the importance of plant-microbe interactions in plant stress response (Bettenfeld et al. 2020; Vacher et al. 2016; Zilber-Rosenberg and Rosenberg 2008). In addition, a better understanding of community ecology of plant endophytes may have implications for improving measures toward their conservation, which is increasingly advocated (Berg et al. 2017; Pandey et al. 2018; van der Heijden et al. 2008).

A decade of microbiome research indicates that environmental filtering (deterministic species-sorting processes that depend on environmental conditions) plays a key role in structuring microbial communities in terrestrial ecosystems (Bahram et al. 2018; Fierer 2017; Peay and Bruns 2014). In addition, plants contribute to the formation of their associated microbial communities using different strategies, including active recruitment of microbes from soil through chemical signaling (Bulgarelli et al. 2012; Finkel et al. 2020; Haney et al. 2015). However, microbes can disperse easily due to their small size and, thus, stochastic distribution of microbes could also contribute to forming microbial communities (Bahram et al. 2016; Coleman-Derr et al. 2016). This may result in a gradient of microbial diversity along the vertical axis from root to 
aboveground organs (Amend et al. 2019; Ottesen et al. 2013) or lack of differentiation among bacterial communities of different tree organs (Haruna et al. 2018). Similarly, leaves may be less dependent on soil as the source of microbiome (Leff et al. 2015, 2017) and their endophytes may originate primarily from the propagules carried with atmospheric air, rain, or insects (Frank et al. 2017; Hodgson et al. 2014; Rodriguez et al. 2009). Thus, microbes originating from these sources are likely more dynamic compared with those aboveground. Aboveground microbial communities might also undergo succession in the perennial tree organs such as trunk and branches whereas, in leaf or flower tissues, their turnover would be relatively fast. However, the relative importance of stochastic and deterministic processes in formation of plant-associated microbial communities remains to be understood, especially as accumulating evidence suggests that soil is a major source of microbiomes in terrestrial habitats (Bahram et al. 2021; Leff et al. 2017; Pent et al. 2017).

Distinct assembly processes may drive the structure of microbial communities across plant individuals with varying contacts to soil and air microbiomes (Amend et al. 2019) and conservation of the compartment differentiation effect has been suggested for annual and perennial hosts (Coleman-Derr et al. 2016; Uroz et al. 2016). On the other hand, certain tree compartments might harbor a greater diversity of microbes by providing more enriched or easily accessible resources and being an ecotone for both above- and belowground communities. For example, the high variation of fungal communities previously observed in trunks (Küngas et al. 2020) might have resulted from sampling together dead and living parts of the wood which have contrasting physicochemical properties. Moreover, sapwood that facilitates the transport of carbohydrates from photosynthesizing parts to the rhizosphere but nutrients and water in the opposite direction (Yadeta and Thomma 2013) could connect below- and aboveground endophytic communities. Contrasting content of nutrients, carbon (Alriksson and Eriksson 1998; Sharrow and Ismail 2004; Thomas and Martin 2012), and antimicrobial compounds (Dastogeer et al. 2020) across different compartments may also affect community structure of bacteria and fungi as well as their interactions (Bahram et al. 2018). Nevertheless, each host species could still include a core microbiotamicrobes occurring in all or most individuals in one or different populations (Vandenkoornhuyse et al. 2015). However, the relative importance of host species identity in structuring the microbiome across different plant compartments remains little known. Despite the pronounced differences in the structure, physiology, and ecology of proversus eukaryotic microbes, their communities in various hosts have mostly been studied separately, with limited analyses combining bacteria and fungi in the forest microbiome (Uroz et al. 2016).

Our study aimed to elucidate the underlying assembly mechanisms of microbial communities across different compartments of tree individuals. For this, we examined fungal and bacterial communities in above- and belowground tree compartments, including leaves, branches, dead wood (trunks), living wood (sapwood), roots of two deciduous tree species (Alnus incana and Betula pubescens), as well as underlying soils in a boreal forest. We hypothesized that, due to contrasting physicochemical properties between different tree compartments (Alriksson and Eriksson 1998), they harbor significantly different microbial community composition. We also hypothesized that microbial communities associated with compartments are structured along the vertical transect of root to leaf depending on their distance to the soil microbiome as a major source of plant-associated microbes.

\section{MATERIALS AND METHODS}

Sampling and preparations. Samples were collected from eutrophic boreo-nemoral forests of Aegopodium site type in Tüki $\left(58^{\circ} 24^{\prime} \mathrm{N}, 26^{\circ} 33^{\prime} \mathrm{E}\right)$ and Kardla $\left(58^{\circ} 25^{\prime} \mathrm{N}, 26^{\circ} 35^{\prime} \mathrm{E}\right)$ in southeastern Estonia in September 2017 (Supplementary Table S1). At each location, we sampled three viable trees of $B$. pubescens and $A$. incana (Betulaceae, Fagales) within $>5 \mathrm{~m}$ distance from each other. For each tree, two 10-cm-long sections were cut from collected three branches taken from lower parts of the crown and five leaves were collected from each of the branches. All of the leaf samples collected from one tree were pooled into one sample in the laboratory. Each $10-\mathrm{cm}$ branch part was cut into four pieces, and the resulting 242.5 $\mathrm{cm}$ sectors from one tree were later crushed and pooled into one sample. Bark was removed with a sterilized knife before sampling from the tree trunk, followed by collecting 0.8 -by- $0.3-\mathrm{cm}$ pieces from the soft layer of living cells following Evans et al. (2003) and Gazis and Chaverri (2010), and separate samples were taken from the underlying inner dead wood by using a sterilized drill of $5 \mathrm{~mm}$ in diameter. Each pair of living and dead wood samples from one tree was taken at three heights $(20,150$, and $170 \mathrm{~cm}$ from the ground), which were pooled into one composite sample for each compartment per tree. Three soil and root subsamples were collected from three locations within $<1 \mathrm{~m}$ distance from each tree trunk, which were pooled and mixed into one soil or coarse and fine root sample per tree in the laboratory. Soil and wood samples were immediately placed in the freezer until they were processed. All of the other samples were processed in the laboratory under a laminar flow hood within $12 \mathrm{~h}$ after collection. All of the leaf, branch, and root samples were surface sterilized using autoclaved distilled water, $70 \%$ ethanol for $2 \mathrm{~min}, 1 \%$ sodium hypochlorite $(\mathrm{NaClO}) 3 \mathrm{~min}$, and $70 \%$ ethanol $1 \mathrm{~min}$; dried for $2 \mathrm{~min}$; and stored at $-30^{\circ} \mathrm{C}$.

Molecular analysis. For DNA extraction from plant samples, we used the Zymo Research Fungal/Bacterial MiniPrep kit and ZymoBIOMICS DNA Miniprep Kit (Zymo Research) and, for soil samples, Zymo Research Soil MiniPrep kit (Zymo Research) following the manufacturer's instructions, with slight modifications to maximize the amount of extracted DNA. Trunk and branch samples were crushed for $5 \mathrm{~min}$ and leaf pieces for $60 \mathrm{~s}$ at $30 \mathrm{~Hz}$ in a Retch MM400 mill in a sterilized metal jar with two 12-mm-diameter sterilized metal beads; for branch and stem samples, an additional $200 \mu \mathrm{l}$ of lysis solution was used and the samples were centrifuged twice in biofuge. The DNA elution step was repeated twice and biofuge revolutions were increased to $14,680 \mathrm{rpm}$.

For amplifying bacterial $16 \mathrm{~S}$ ribosomal DNA (rDNA), the primers 515F and 806R (Caporaso et al. 2012) were used and the following PCR protocol was used: $95^{\circ} \mathrm{C}$ for $15 \mathrm{~min}$; 28 to 30 cycles of $95^{\circ} \mathrm{C}$ for $30 \mathrm{~s}, 50^{\circ} \mathrm{C} 45 \mathrm{~s}$, and $72^{\circ} \mathrm{C}$ for $1 \mathrm{~min}$; with a final extension step at $72^{\circ} \mathrm{C}$ for $10 \mathrm{~min}$. For amplifying the rDNA internal transcribed spacer (ITS) 2 region from fungi, we used a mix of ITS3 primer in combination with ITS4ngsUni, as described by Tedersoo et al. (2014). Two PCR assays were set up for each sample, one using $10 \mu \mathrm{l}$ and the other $2 \mu \mathrm{l}$ of the DNA extract, with the total volume of $25 \mu \mathrm{l}$ consisting of $5 \mu \mathrm{l}$ of Solis Biodyne PCRmix, $0.5 \mu \mathrm{l}$ of ITS3mix, $0.5 \mu \mathrm{l}$ of ITS4 primer, and 9 or $17 \mu \mathrm{l}$ of distilled water. PCR was run under the following conditions: at $95^{\circ} \mathrm{C}$ for $15 \mathrm{~min} ; 33$ cycles at $94^{\circ} \mathrm{C}$ for $30 \mathrm{~s}, 55^{\circ} \mathrm{C}$ for $30 \mathrm{~s} \mathrm{~s}$, and $72^{\circ} \mathrm{C}$ for $1 \mathrm{~min}$; and a final step at $72^{\circ} \mathrm{C}$ for $10 \mathrm{~min}$. To account for contamination and cross contamination during molecular analyses, positive and negative controls were used. Both fungal and bacterial PCR products were separated by electrophoresis using a $1 \%$ agarose gel in $0.5 \times$ Tris-borate EDTA buffer $(45 \mathrm{mM}$ Tris base, $45 \mathrm{mM}$ boric acid, and $1 \mathrm{mM}$ EDTA; pH8.0) and visualized under UV light. PCR products were purified using a FavorPrep Gel/PCR Purification Mini kit (Biotech Corp.). DNA concentration was measured using a Qubit 2.0 Fluorometer (Invitrogen Life Technologies Corp.) for purification and mixing. All PCR products with visible bands were normalized based on the comparison of band intensity and 
were sequenced at the Estonian Biocentre using Illumina MiSeq high-throughput sequencing platform. All raw sequences were deposited at NCBI's Sequence Read Archive under accession number PRJNA763884.

Bioinformatics. Paired-end reads from the Illumina MiSeq data were assembled, quality filtered, demultiplexed, chimera filtered, and clustered, and the preliminary taxonomy was assigned using LotuS (Hildebrand et al. 2014). To generate operational taxonomic units (OTUs), quality-filtered sequences were clustered twice using 97\% similarity threshold (USEARCH through LotuS for fungi and SILVA for bacteria). For taxonomic identification of the reference sequences of the resulting OTUs, we used the GenBank, UNITE (Kõljalg et al. 2013), and SILVA (Quast et al. 2012) databases. Applying the latest advancements in the UNITE database (Kõljalg et al. 2020) enabled us to assign the detected fungi to species hypotheses $(\mathrm{SH})$ and map the taxonomy, EcM lineages, and interacting taxa known for each $\mathrm{SH}$. These taxonomic assignments were used to update the fungal taxonomy table; NCBI BLAST search was further used for OTUs unassigned to higher level taxa. Fungal SHs and genera were assigned to functional groups using FungalTraits (Põlme et al. 2020).

Statistical analyses. Abundance matrices were rarefied to the median number of reads across samples and further normalized using Hellinger transformation using the vegan package of $\mathrm{R}$ (version 2.5-6) (Oksanen et al. 2007). To characterize species diversity in different samples, Shannon diversity index was used in vegan. Mantel statistics were used to test whether community dissimilarity between samples correlated with their distance from soil samples. Principal coordinates analysis in vegan was used to visualize the community variation across samples. Tukey's honestly significant difference test was further used to test how fungal and bacterial OTUs are distributed in samples. Permutational analysis of variance (PERMANOVA) of the distance matrices was used to determine interactions and the effect of factors on fungal and bacterial communities using the adonis 2 function of vegan (Oksanen et al. 2007). Analysis of similarities was further used to determine pairwise differences in community composition between compartments. To further determine OTUs significantly associated with each compartment, we performed an indicator species analysis as implemented in the labdsv package (version 2.0-1). To test the effect of nestedness and community turnover on community variation across samples, community variation was separated into OTU turnover and loss or gain as implemented in the betapart package (version 1.5.1) (Baselga and Orme 2012). To test whether communities across or within compartments or habitats are nested within each other, we used the 'nestedness metric based on overlap and decreasing fill' (Almeida-Neto and Ulrich 2011) as implemented in the NODF function in vegan. Furthermore, a Bayesian approach was used to estimate the proportion of plant-associated microbes that potentially originate from soils, as implemented in the Sourcetracker2 package (Knights et al. 2011). This analysis allowed us to determine a source environment for OTUs in sink samples.

\section{RESULTS}

In total, 1,057,964 bacterial sequences (on average, 12,594 per sample) were obtained, mostly from tree parts (72\%) followed by soil (28\%). For fungi, quality filtering and the exclusion of nonfungal sequences resulted in 377,246 reads (on average, 4,491 per sample), of which $62.5 \%$ originated from plant samples and $37.5 \%$ from soil (Supplementary Table S2). The bacterial/fungal abundance ratio varied at large scale among the six tree compartments and soil (Supplementary Fig. S1). Clustering of reads resulted in 4,290 bacterial and 1,500 fungal OTUs; in aboveground tree compartments, bacterial OTU numbers were, on average, 1.5 (in leaves) to 5 (in dead wood) but 11.5 times bigger in root tips and 13.5 times bigger in coarse roots than those of fungi, with a $21: 1$ ratio recorded from soil (Supplementary Fig. S1). Bacterial communities were dominated by Alphaproteobacteria, Gammaproteobacteria, and Betaproteobacteria across trees but by Planctomycetia, Alphaproteobacteria, and Deltaproteobacteria in soil (Supplementary Table S2). Although Acidobacteriales, Actinomycetales, Rhizobiales, and Rhodospirillales had higher abundance in aboveground tree compartments, the share of Acidimicrobiales, Gaiellales, Gemmatales, Myxococcales, Pedosphaerales, and Pirellulales was higher in belowground samples, including soil (Supplementary Fig. S1). Dothideomycetes, in particular its orders Pleosporales and Capnodiales, and Eurotiomycetes (Chaetothyriales) were more abundant in aboveground fungal communities whereas Agaricomycetes (orders Agaricales, Thelephorales, and Russulales) and Leotiomycetes (Helotiales) dominated the belowground samples (Supplementary Fig. S1; Supplementary Table S2). The dominant functional guilds in soil and root samples were ectomycorrhizal and saprotrophic fungi (Supplementary Table S3) whereas foliar endophytes and plant pathogens dominated in leaves and branches. Plant pathogens were detected in all habitats but were relatively more abundant in leaves.

PERMANOVA analysis indicated that plant compartments (excluding soil samples) were the primary determinant of community structure of bacteria and fungi, explaining $44.0 \%(F=10.37 P=0.001)$ and $28.9 \%(F=5.38, P=0.001)$ of their community variation, respectively (Fig. 1). The host species explained 3.8 and $3.5 \%$ of community structure of both bacteria and fungi, respectively (bacteria: $F=3.28$, $P=0.001$; and fungi: $F=3.03, P=0.001$ ), while the effects of site and individual trees remained negligible $(P>0.01)$. The frequencies of OTU occurrences in different compartments of the two hosts were highly correlated (bacteria: $R=0.929, P<0.001$; and fungi: $R=0.892, P<0.001$ ), further indicating a weak host effect. In total, 215 (204 bacteria and 11 fungi) and 118 (112 bacteria and 6 fungi) OTUs were present in all compartments of Alnus and Betula spp., respectively. Bacteria of the core microbiota belonged mainly to Burkholderiales, Rhizobiales, Sphingomonadales (Proteobacteria), and Actinomycetales (Actinobacteria) whereas fungi represented various classes (Supplementary Table S4). Bacterial communities showed a greater distinction between below- and aboveground habitats compared with fungal communities (bacteria: $F=33.89, R^{2}=0.292$, $P=0.001$; and fungi: $F=10.14, R^{2}=0.110, P=0.001$ ). In particular, bacterial communities associated with leaf samples were markedly different from those in soil (Fig. 2). Pairwise comparison of community variation between the same compartment from different hosts indicated a stronger effect of the host in shaping of aboveground microbial communities compared with those belowground (Supplementary Table S5). Only fungal communities showed significant differences between belowground compartments of the two studied hosts (Supplementary Table S5).

We also found that distance from soil more strongly determined the community structure of bacteria, compared with fungi (bacteria: $R^{2}=0.247, P=0.001$; and fungi: $\left.R^{2}=0.101, P=0.001\right)$. Both bacterial and fungal communities were more variable in aboveground than belowground compartments (Supplementary Fig. S2). Communities of both bacteria and fungi were increasingly more dissimilar with increasing spatial distance between habitat types (Mantel tests; bacteria: Mantel $r=0.695, P=0.001$; and fungi: Mantel $r=0.527, P=0.001$ ) (Fig. 3). For bacteria, closely located habitats appear to share more OTUs compared with fungi, as reflected in the stronger decline of bacterial community similarity across habitats (Fig. 3). Pairwise comparison of community composition among habitat types, including all below- and aboveground habitat pairs, revealed significant differences in eight pairs of 
bacterial communities but only one pair of fungal communities (Supplementary Fig. S3). The bacterial communities were particularly different between roots and leaves as well as soil and leaves (Figs. 1 and 3). Disentangling the community variation into OTU turnover and loss or gain on community dissimilarities between samples revealed that, for fungi, most of the cross-compartment variation is due to OTU turnover (Mantel $r=0.492, P=0.001$ ) but not OTU loss or gain $(P>0.1)$ whereas, for bacteria, it relates to both OTU turnover (Mantel $r=0.352, P=0.001$ ) as well as OTU loss or gain (Mantel $r=0.543, P=0.001$ ) (Supplementary Fig. S4). This was further supported by a greater nestedness in bacterial communities across habitat types compared with fungal communities (Fig. 4). Compared with other tree compartments, microbial OTUs associated with dead wood samples showed a greater overlap with both soil and aboveground compartments (Fig. 4). The sourcetracking analysis further supported the idea that dead wood harbors a significantly greater proportion of OTUs originating from soil compared with other aboveground compartments (Supplementary Fig. S5). In addition, communities of bacteria in belowground compartments showed greater nestedness compared with aboveground compartments whereas, for fungi, overall nestedness was weak and comparable in different compartments (Supplementary Table S6).

Microbial diversity (Shannon index) differed significantly between aboveground and belowground tree compartments for bacteria $(F=$ $\left.40.4, R^{2}=0.357, P<0.001\right)$ but not for fungi $(P=0.839)$. Both bacterial and fungal diversity declined from soil to aboveground compartments. The greatest diversity of bacteria and, to a less pronounced extent, fungi was found in root and dead wood samples, whereas living wood harbored the lowest diversity (Fig. 5). The effect of host and site on microbial diversity was nonsignificant $(P>0.05)$.

Indicator species analysis revealed the greatest number of bacterial and fungal indicator OTUs in root tips (13.6\%) and branches (38.5\%) compared with other compartments, respectively (Supplementary Table S7). Most indicator bacterial OTUs of aboveground tree compartments belonged to the class Alphaproteobacteria (43.0\%), whereas those of belowground compartments mostly belonged to Planctomycetia (15.2\%). For fungi, most of the indicator OTUs of above- and belowground compartments belonged to Dothideomycetes $(29.7 \%)$ and Leotiomycetes $(37.0 \%)$, respectively.

\section{DISCUSSION}

Despite the key role of microbes in plant health and functioning, the key determinants of community assembly and diversity of plant associated microbes remain largely unknown. Our study demonstrates that the spatial distance of plant compartments from soil strongly determines the structure of their associated microbial communities. This finding is in line with source-sink dynamics in a metacommunity (Mouquet and Loreau 2003); that is, soil microbial communities act as a source of the tree microbiome, especially for compartments near the soil, reflected in the increasing distinctness of microbial communities along the increasing physical distance from soil.

We also found that, as an intermediate habitat equally exposed to soil and air microbiomes, microbial communities associated with dead wood samples from the trunk showed the highest overlap with those in above- and belowground compartments (Fig. 4). Dead wood also harbored a diversity of microbes comparable with belowground compartments and was the only aboveground compartment with a significant proportion of OTUs originating from soil (Supplementary Fig. S5). Highest microbial community variation in dead wood suggests that dead wood may be inhabited by microbes entering through roots and bark surface as well as stomata in leaves. Indeed, foliar endophytes have been shown to be able to colonize woody substrates directly from leaves (Nelson et al. 2020). By contrast, living wood samples showed the lowest diversity in our dataset, and their microbial communities were more similar to those in leaves and branches than to those in roots. These data suggest that, in healthy trees, the living wood facilitates the transfer of microbes along the nutrient-rich phloem from leaves downward rather than their proliferation via the nutrient-poor xylem vessels from soil through the roots to the aboveground compartments, as is known for various vascular pathogens (Yadeta and Thomma 2013). Significant differences in fungal richness and community composition also have
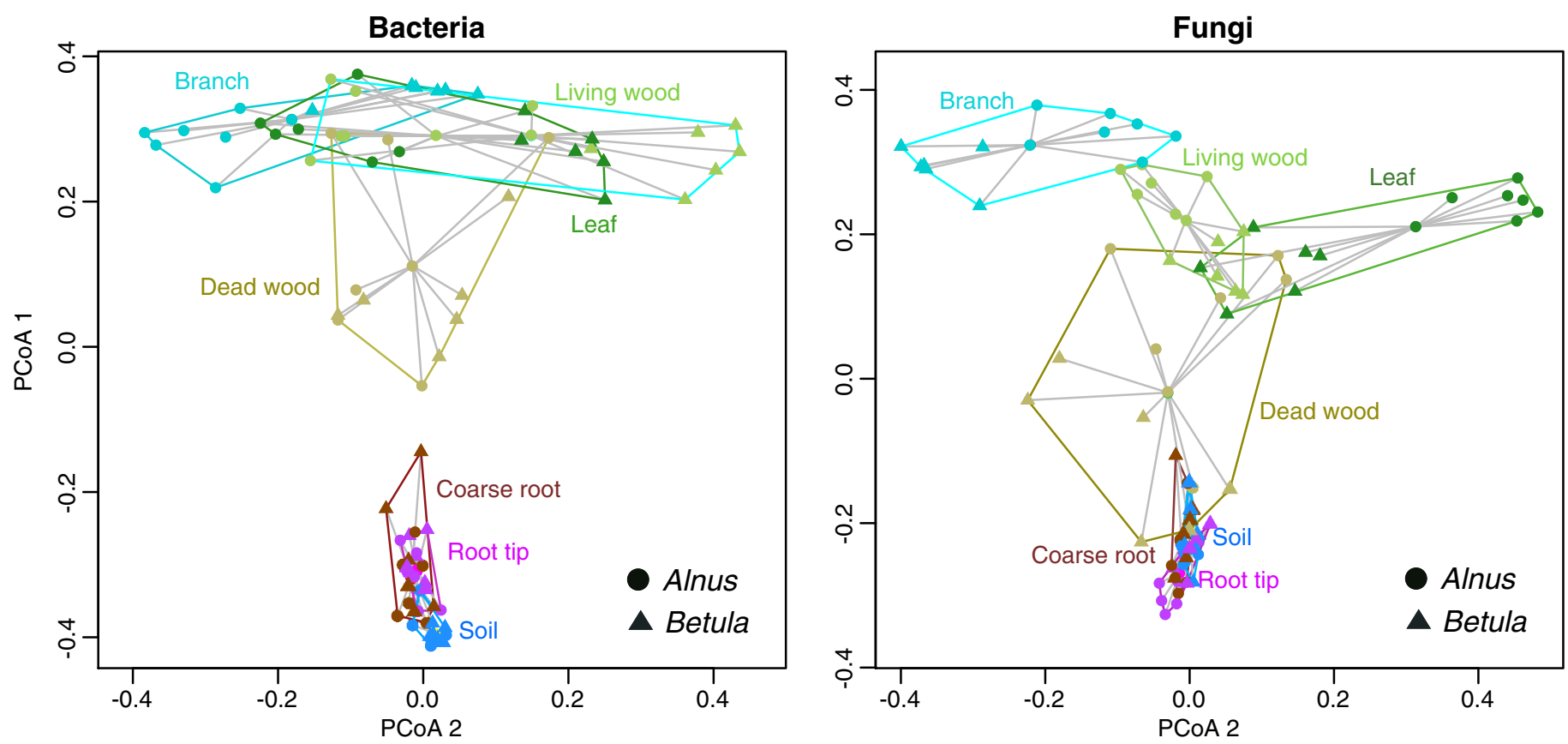

Fig. 1. Variability of microbial communities among tree compartments below- and aboveground. Principal coordinate analysis (PCoA) showing Bray-Curtis dissimilarities between different compartments. Soil samples were included for comparison. 

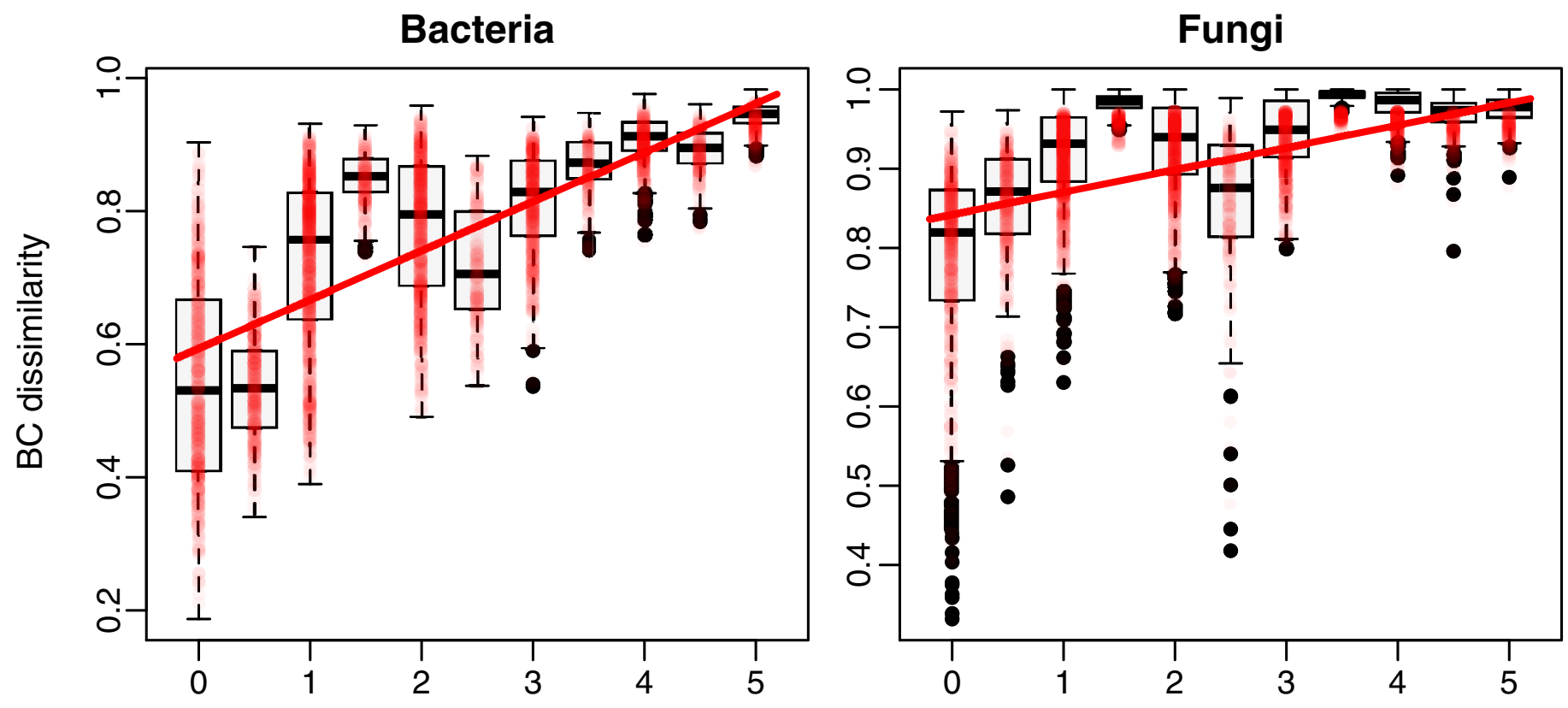

Vertical distance

Fig. 2. Stronger distance decay of community similarities for bacteria than fungi across the vertical transect of soil to leaf. $B C=B r a y-C u r t i s$.

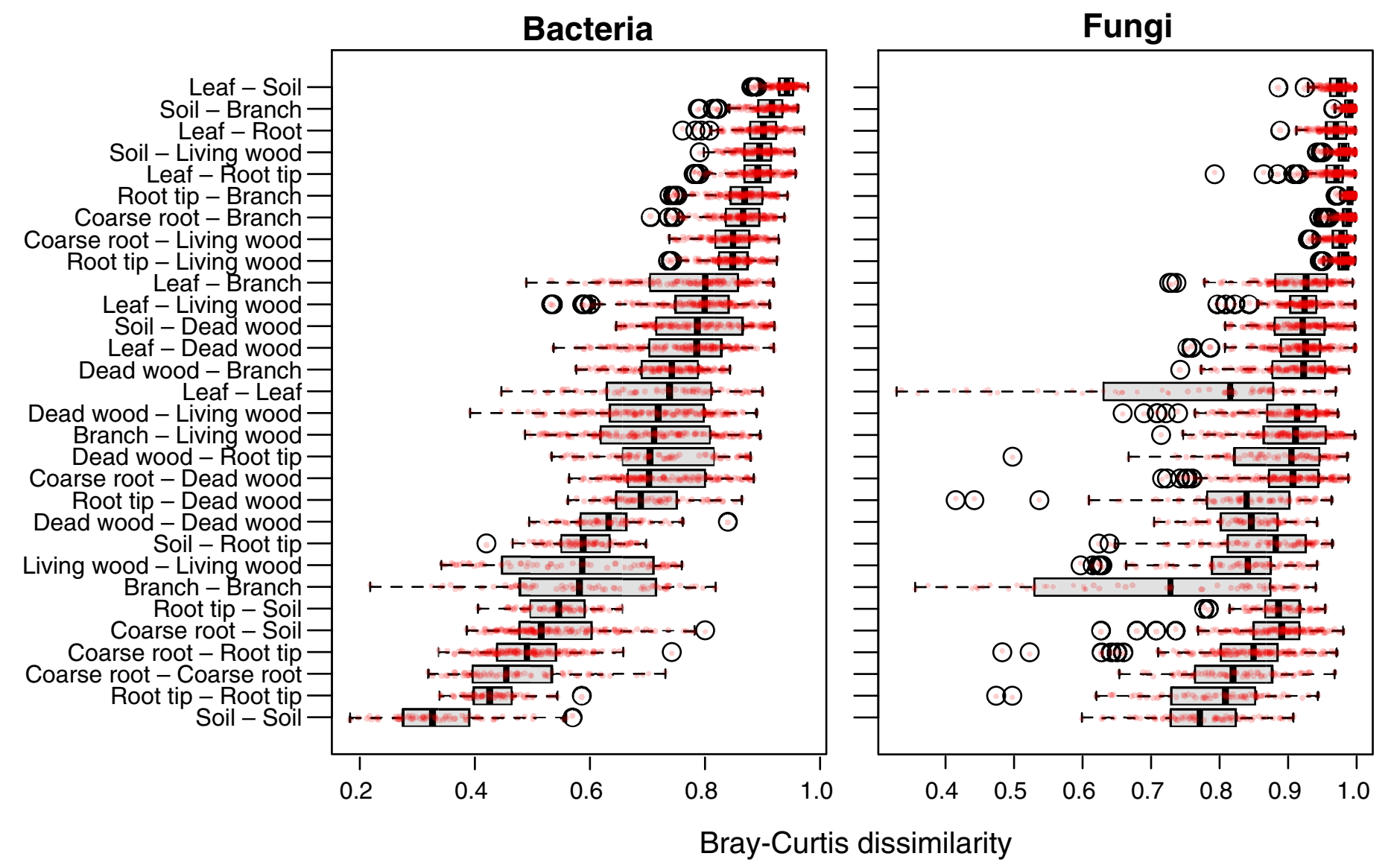

Fig. 3. Pairwise comparison of microbial community composition associated with tree compartment as well as soil samples. Pairwise comparisons are ordered according to median Bray-Curtis distances for bacteria. 
been found between sapwood and heartwood in case of decaying wood of coniferous and deciduous tree species (Kubartová et al. 2012; van der Wal et al. 2016), with higher diversity or abundance observed in heart- and sapwood, respectively (Johnston et al. 2016).

The composition of microbial communities of aboveground compartments of trees, especially fungal communities in dead wood, was more variable than that in roots and soil. This finding can be explained by more stable habitat conditions belowground, or by the fact that microbial communities in aboveground compartments originate at least partly from bacterial cells and fungal spores in the air, where these are likely more dynamic and have greater dispersal potential compared with soil microbes. By contrast, bacterial diversity declined on the soil-roots-trunk-crown transect, although this pattern was less pronounced for fungi. These results are partly in line with a previous study on the Populus holobiont, which reported an increased bacterial diversity from leaves to soil habitats and an increased fungal diversity in tree stems followed by underlying soil (Cregger et al. 2018). These results may reflect low inoculation rates of bacteria from the air and their lower potential to disseminate across tree compartments compared with fungi.

Although the importance of soil as a source of microbiome has been shown for various habitats (Bahram et al. 2021; Bonito et al. 2014; Frank et al. 2017; Leff et al. 2017), how this may vary across a plant individual remains little known (Amend et al. 2019). The observed differences in assembly processes across different tree compartments in our study may result from variation in carbon, nutrient, and water content as well as $\mathrm{pH}$ among plant compartments, known to be important in shaping microbial communities in decaying wood (Purahong et al. 2018), in addition to differences in the abundance of living cells (Johnston et al. 2016). Indeed, we observed considerable overlap among microbial communities of leaves and living wood, likely due to their greater number of living cells and, therefore, protein and simple sugar content compared with other tree compartments.

Despite limited phylogenetic extent among host species, both belonging to the family Betulaceae in our study, we found great differences in the composition of microbial communities between the same aboveground compartments from the two host species. The effect of host identity on the structure of microbial communities was particularly strong in aboveground compartments compared with those belowground (Supplementary Table S5). Several studies have demonstrated the effect of host rather than environmental conditions in structuring microbiomes of annual plants (Bergelson et al. 2019; Christian et al. 2016; Harrison et al. 2018). The structure of endophytic communities has been reported to be influenced primarily by specific host factors such as production of tissue-specific metabolites (Horton et al. 2014) and plant-microbe communication (Lareen et al. 2016). Other studies on endophytes in aboveground compartments of trees have also emphasized the host identity effect (Sun et al. 2012; Unterseher et al. 2012), with class-level distinction between microbial dominants of gymno- and angiosperms (Uroz et al. 2016). Nevertheless, fungal communities showed significant differences in associating with the hosts studied here, which may reflect their greater host specificity compared with bacteria.

Compared with fungal communities, bacterial communities showed greater specificity and distinction across belowground and aboveground compartments. Fungal communities revealed a weaker distance decay pattern of similarity across the vertical transect, which was mainly due to the greater similarity between samples from a particular compartment and those next to it (Fig. 3). Although we cannot exclude the role of dispersal limitation in structuring microbial communities even on a fine scale (Adams et al. 2013), which is known to be more important for fungi than bacteria (Bahram et al. 2018; Vannette et al. 2020), the more pronounced vertical stratification of communities of bacteria than fungi in our study may be
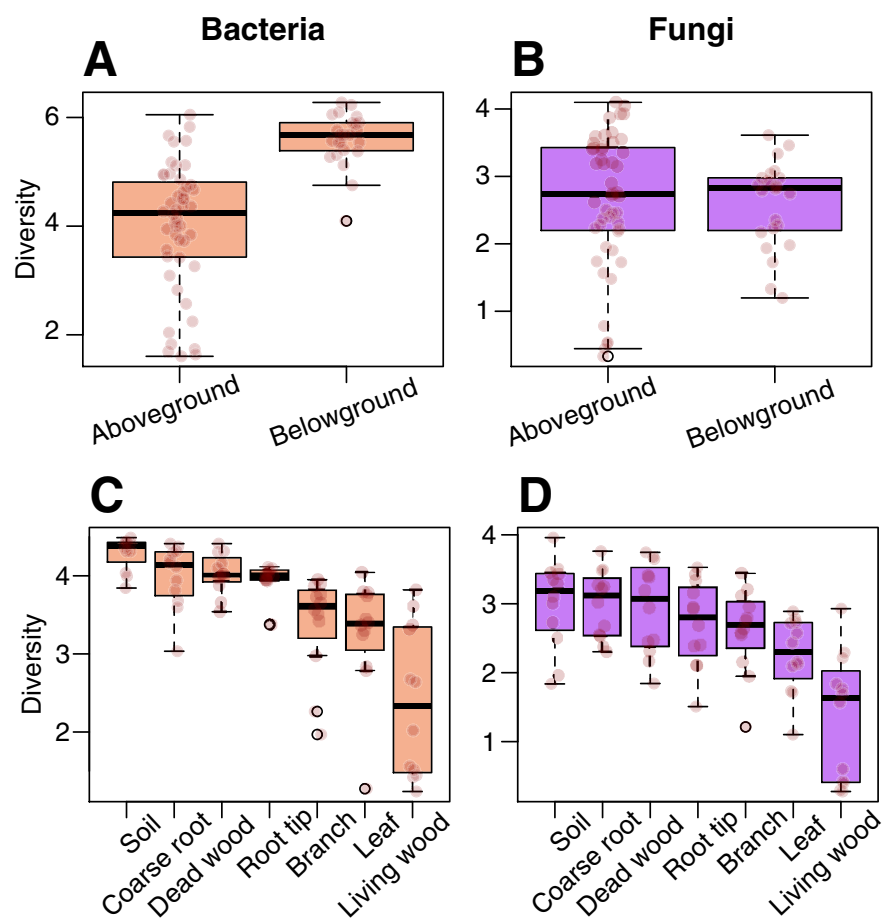

Fig. 5. Diversity of microbial communities associated with tree compartments. Boxplots showing microbial operational taxonomic unit diversity across $\mathbf{A}$ and $\mathbf{B}$, belowground and aboveground habitats and $\mathbf{C}$ and $\mathbf{D}$, compartments in tree-associated microbial communities.

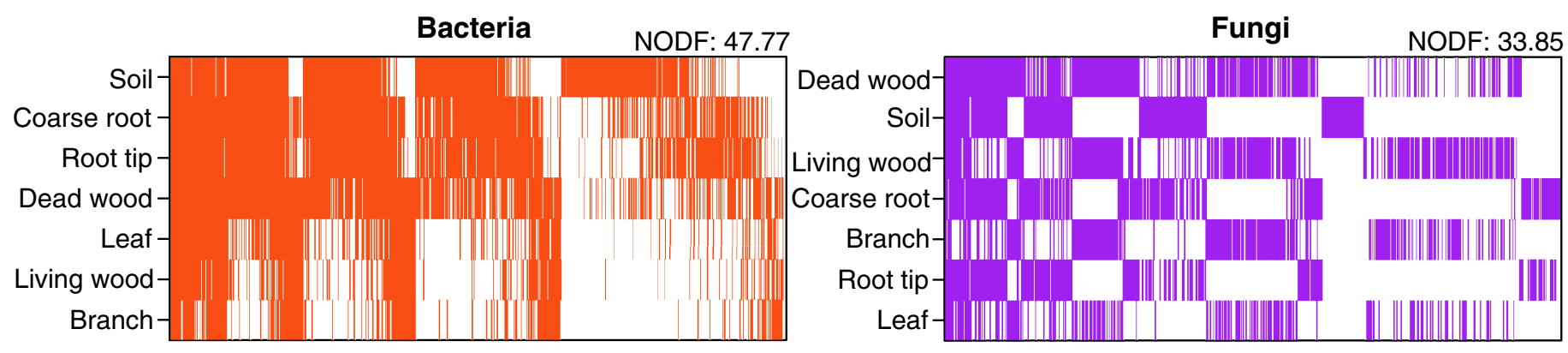

Fig. 4. Microbial communities of different tree organs are nested within each other. Filled cells represent the occurrence of operational taxonomic units (OTUs) (columns) in each habitat type (rows). OTU tables were aggregated by habitat type and further rarefied to the lowest number of reads per organ (8,593 for bacteria and 14,129 for fungi). 
related to stronger effects of habitat filtering on bacterial communities. In support of this, we found that bacteria form more nested communities across below- and aboveground compartments compared with fungi, despite the fact that, in rRNA, the $16 \mathrm{~S}$ gene is more conserved than the ITS region used for their metabarcoding, respectively. This finding is in line with several recent reports showing that bacterial communities are more strongly structured by environmental filtering whereas an interplay of deterministic and neutral processes shape fungal communities (Bahram et al. 2018, 2020; Bernard et al. 2021; de Vries et al. 2018). Our results extend previous findings by showing that, even on a very fine level, the mechanisms shaping bacterial and fungal communities may be fundamentally different (Bahram et al. 2018), likely due to differences in their life forms, physiology, population dynamics, and dispersal capacity (Frey-Klett et al. 2011; Kim and Lee 2020; Reischke et al. 2014). The implications of such differences for the host performance and health remain to be investigated.

Conclusions. This study sheds light on the structure of microbial communities in woody plants in relation to surrounding soils. Our results indicate a strong vertical stratification in the structure of microbial communities in woody plants, reflecting the important role of the soil environment in the formation of plant microbiomes. The strong association between the soil microbiome and plant endophytes highlights the need to consider soil conditions for functioning of a healthy plant holobiome as well as to protect plant endophytes. In addition, the impact of host identity, regarded as one of the main determinants of plant microbial communities, appears to vary considerably between tree compartments as well as between bacteria and fungi. The finding that bacteria show a more distinct pattern compared with fungi across aboveground and belowground tree compartments may reflect their contrasting community assembly processes. Further work is needed to understand the role of plant biochemical and physiological traits and microbes in the surrounding air in forming microbial communities in plant tissues and organs.

\section{ACKNOWLEDGMENTS}

We thank R. Puusepp for assistance in the molecular lab, A. Sellin for useful comments on the manuscript, and C. Schadt and an anonymous reviewer for helpful comments on the manuscript.

\section{LITERATURE CITED}

Adams, R. I., Miletto, M., Taylor, J. W., and Bruns, T. D. 2013. Dispersal in microbes: Fungi in indoor air are dominated by outdoor air and show dispersal limitation at short distances. ISME J. 7:1262-1273.

Almeida-Neto, M., and Ulrich, W. 2011. A straightforward computational approach for measuring nestedness using quantitative matrices. Environ. Model. Softw. 26:173-178.

Alriksson, A., and Eriksson, H. M. 1998. Variations in mineral nutrient and $\mathrm{C}$ distribution in the soil and vegetation compartments of five temperate tree species in NE Sweden. For. Ecol. Manage. 108:261-273.

Amend, A. S., Cobian, G. M., Laruson, A. J., Remple, K., Tucker, S. J., Poff, K. E., Antaky, C., Boraks, A., Jones, C. A., Kuehu, D., Lensing, B. R., Pejhanmehr, M., Richardson, D. T., and Riley, P. P. 2019. Phytobiomes are compositionally nested from the ground up. PeerJ 7:e6609.

Bahram, M., Hildebrand, F., Forslund, S. K., Anderson, J. L., Soudzilovskaia, N. A., Bodegom, P. M., Bengtsson-Palme, J., Anslan, S., Coelho, L. P., Harend, H., and Huerta-Cepas, J. 2018. Structure and function of the global topsoil microbiome. Nature 560:233-237.

Bahram, M., Kohout, P., Anslan, S., Harend, H., Abarenkov, K., and Tedersoo, L. 2016. Stochastic distribution of small soil eukaryotes resulting from high dispersal and drift in a local environment. ISME J. 10:885-896.

Bahram, M., Netherway, T., Frioux, C., Ferretti, P., Coelho, L. P., Geisen, S., Bork, P., and Hildebrand, F. 2021. Metagenomic assessment of the global diversity and distribution of bacteria and fungi. Environ. Microbiol. 23:316-326.

Bahram, M., Netherway, T., Hildebrand, F., Pritsch, K., Drenkhan, R., Loit, K., Anslan, S., Bork, P., and Tedersoo, L. 2020. Plant nutrient-acquisition strategies drive topsoil microbiome structure and function. New Phytol. 227:1189-1199.

Baselga, A., and Orme, C. D. L. 2012. betapart: An R package for the study of beta diversity. Methods Ecol. Evol. 3:808-812.

Berg, G., Köberl, M., Rybakova, D., Müller, H., Grosch, R., and Smalla, K. 2017. Plant microbial diversity is suggested as the key to future biocontrol and health trends. FEMS Microbiol. Ecol. 93:fix050.

Bergelson, J., Mittelstrass, J., and Horton, M. W. 2019. Characterizing both bacteria and fungi improves understanding of the Arabidopsis root microbiome. Sci. Rep. 9:24.

Bernard, J., Wall, C. B., Costantini, M. S., Rollins, R. L., Atkins, M. L., Cabrera, F. P., Cetraro, N. D., Feliciano, C. K., Greene, A. L., Kitamura, P. K., Olmedo-Velarde, A., Sirimalwatta, V. N. S., Sung, H. W., Thompson, L. P. M., Vu, H. T., Wilhite, C. J., and Amend, A. S. 2021. Plant part and a steep environmental gradient predict plant microbial composition in a tropical watershed. ISME J. 15:999-1009.

Bettenfeld, P., Fontaine, F., Trouvelot, S., Fernandez, O., and Courty, P.-E. 2020. Woody plant declines. What's wrong with the microbiome? Trends Plant Sci. 25:381-394.

Bonito, G., Reynolds, H., Robeson, M. S., Nelson, J., Hodkinson, B. P., Tuskan, G., Schadt, C. W., and Vilgalys, R. 2014. Plant host and soil origin influence fungal and bacterial assemblages in the roots of woody plants. Mol. Ecol. 23:3356-3370.

Bulgarelli, D., Rott, M., Schlaeppi, K., van Themaat, E. V. L., Ahmadinejad, N., Assenza, F., Rauf, P., Huettel, B., Reinhardt, R., Schmelzer, E., Peplies, J., Gloeckner, F. O., Amann, R., Eickhorst, T., and SchulzeLefert, P. 2012. Revealing structure and assembly cues for Arabidopsis root-inhabiting bacterial microbiota. Nature 488:91-95.

Caporaso, J. G., Lauber, C. L., Walters, W. A., Berg-Lyons, D., Huntley, J., Fierer, N., Owens, S. M., Betley, J., Fraser, L., Bauer, M., Gormley, N., Gilbert, J. A., Smith, G., and Knight, R. 2012. Ultra-high-throughput microbial community analysis on the Illumina HiSeq and MiSeq platforms. ISME J. 6:1621-1624.

Christian, N., Sullivan, C., Visser, N. D., and Clay, K. 2016. Plant host and geographic location drive endophyte community composition in the face of perturbation. Microb. Ecol. 72:621-632.

Coleman-Derr, D., Desgarennes, D., Fonseca-Garcia, C., Gross, S., Clingenpeel, S., Woyke, T., North, G., Visel, A., Partida-Martinez, L. P., and Tringe, S. G. 2016. Plant compartment and biogeography affect microbiome composition in cultivated and native Agave species. New Phytol. 209:798-811.

Cregger, M. A., Veach, A. M., Yang, Z. K., Crouch, M. J., Vilgalys, R., Tuskan, G. A., and Schadt, C. W. 2018. The Populus holobiont: Dissecting the effects of plant niches and genotype on the microbiome. Microbiome 6:31.

Dastogeer, K. M., Tumpa, F. H., Sultana, A., Akter, M. A., and Chakraborty, A. 2020. Plant microbiome-An account of the factors that shape community composition and diversity. Curr. Plant Biol. 23:100161.

de Vries, F. T., Griffiths, R. I., Bailey, M., Craig, H., Girlanda, M., Gweon, H. S., Hallin, S., Kaisermann, A., Keith, A. M., Kretzschmar, M., Lemanceau, P., Lumini, E., Mason, K. E., Oliver, A., Ostle, N., Prosser, J. I. Thion, C., Thomson, B., and Bardgett, R. D. 2018. Soil bacterial networks are less stable under drought than fungal networks. Nat. Commun. 9:3033.

Evans, H. C., Holmes, K. A., and Thomas, S. E. 2003. Endophytes and mycoparasites associated with an indigenous forest tree, Theobroma gileri, in Ecuador and a preliminary assessment of their potential as biocontrol agents of cocoa diseases. Mycol. Prog. 2:149-160.

Fierer, N. 2017. Embracing the unknown: Disentangling the complexities of the soil microbiome. Nat. Rev. Microbiol. 15:579-590.

Finkel, O. M., Salas-González, I., Castrillo, G., Conway, J. M., Law, T. F., Teixeira, P. J., Wilson, E. D., Fitzpatrick, C. R., Jones, C. D., and Dangl, J. L. 2020. A single bacterial genus maintains root growth in a complex microbiome. Nature 587:103-108.

Frank, A. C., Saldierna Guzmán, J. P., and Shay, J. E. 2017. Transmission of bacterial endophytes. Microorganisms 5:70.

Frey-Klett, P., Burlinson, P., Deveau, A., Barret, M., Tarkka, M., and Sarniguet, A. 2011. Bacterial-fungal interactions: Hyphens between agricultural, clinical, environmental, and food microbiologists. Microbiol. Mol. Biol. Rev. 75:583-609. 
Gazis, R., and Chaverri, P. 2010. Diversity of fungal endophytes in leaves and stems of wild rubber trees (Hevea brasiliensis) in Peru. Fungal Ecol. 3:240-254

Haney, C. H., Samuel, B. S., Bush, J., and Ausubel, F. M. 2015. Associations with rhizosphere bacteria can confer an adaptive advantage to plants. Nat. Plants 1:15051.

Harrison, J. G., Parchman, T. L., Cook, D., Gardner, D. R., and Forister, M. L. 2018. A heritable symbiont and host-associated factors shape fungal endophyte communities across spatial scales. J. Ecol. 106:2274-2286.

Haruna, E., Zin, N. M., Kerfahi, D., and Adams, J. M. 2018. Extensive overlap of tropical rainforest bacterial endophytes between soil, plant parts, and plant species. Microb. Ecol. 75:88-103.

Hildebrand, F., Tadeo, R., Voigt, A. Y., Bork, P., and Raes, J. 2014. LotuS: An efficient and user-friendly OTU processing pipeline. Microbiome 2:30.

Hodgson, S., de Cates, C., Hodgson, J., Morley, N. J., Sutton, B. C., and Gange, A. C. 2014. Vertical transmission of fungal endophytes is widespread in forbs. Ecol. Evol. 4:1199-1208.

Horton, M., Bodenhausen, N., Beilsmith, K., Meng, D., Muegge, B. D., Subramanian, S., Vetter, M. M., Vihjalmsson, B. J., Nordborg, M., Gordon, I. J., and Bergelson, J. 2014. Genome-wide association study of Arabidopsis thaliana leaf microbial community. Nat. Commun. 5:5320.

Johnston, S. R., Boddy, L., and Weightman, A. J. 2016. Bacteria in decomposing wood and their interactions with wood-decay fungi. FEMS Microbiol. Ecol. 92:fiw179.

Kim, H., and Lee, Y. H. 2020. The rice microbiome: A model platform for crop holobiome. Phytobiomes J. 4:5-18.

Knights, D., Kuczynski, J., Charlson, E. S., Zaneveld, J., Mozer, M. C., Collman, R. G., Bushman, F. D., Knight, R., and Kelley, S. T. 2011. Bayesian communitywide culture-independent microbial source tracking. Nat. Methods 8:761-763.

Kõljalg, U., Nilsson, H. R., Schigel, D., Tedersoo, L., Larsson, K. H., May, T. W., Taylor, A. F., Jeppesen, T. S., Frøslev, T. G., Lindahl, B. D., Põldmaa, K., Saar, I., Suija, A., Savchenko, A., Yatsiuk, I., Adojaan, K., Ivanov, F., Piirmann, T., Pöhönen, R., Zirk, A., and Abarenkov, K. 2020 The taxon hypothesis paradigm-On the unambiguous detection and communication of taxa. Microorganisms 8:1910.

Kõljalg, U., Nilsson, R. H., Abarenkov, K., Tedersoo, L., Taylor, A. F., Bahram, M., Bates, S. T., Bruns, T. D., Bengtsson-Palme, J., Callaghan, T. M., Douglas, B., Drenkhan, T., Eberhardt, U., Dueñas, M., Grebenc, T., Griffith, G. W., Hartmann, M., Kirk, P. M., Kohout, P., Larsson, E., Lindahl, B. D., Lücking, R., Martín, M. P., Matheny, P. B., Nguyen, N. H., Niskanen, T., Oja, J., Peay, K. G., Peintner, U., Peterson, M., Põldmaa, K., Saag, L., Saar, I., Schüßler, A., Scott, J. A., Senés, C., Smith, M. E., Suija, A., Taylor, D. L., Telleria, M. T., Weiss, M., and Larsson, K.-H. 2013. Towards a unified paradigm for sequence-based identification of fungi. Mol. Ecol. 22:5271-5277.

Kubartová, A., Ottosson, E., Dahlberg, A., and Stenlid, J. 2012. Patterns of fungal communities among and within decaying logs, revealed by 454 sequencing. Mol. Ecol. 21:4514-4532.

Küngas, K., Bahram, M., and Põldmaa, K. 2020. Host tree organ is the primary driver of endophytic fungal community structure in a hemiboreal forest. FEMS Microbiol. Ecol. 96:fiz199.

Lareen, A., Burton, F., and Schäfer, P. 2016. Plant root-microbe communication in shaping root microbiomes. Plant Mol. Biol. 90:575-587.

Leff, J. W., Del Tredici, P., Friedman, W. E., and Fierer, N. 2015. Spatial structuring of bacterial communities within individual Ginkgo biloba trees. Environ. Microbiol. 17:2352-2361.

Leff, J. W., Lynch, R. C., Kane, N. C., and Fierer, N. 2017. Plant domestication and the assembly of bacterial and fungal communities associated with strains of the common sunflower, Helianthus annuus. New Phytol. 214:412-423.

Lundberg, D. S., Lebeis, S. L., Paredes, S. H., Yourstone, S., Gehring, J., Malfatti, S., Tremblay, J., Engelbrektson, A., Kunin, V., Del Rio, T. G., and Edgar, R. C. 2012. Defining the core Arabidopsis thaliana root microbiome. Nature 488:86-90.

Mouquet, N., and Loreau, M. 2003. Community patterns in source-sink metacommunities. Am. Nat. 162:544-557.

Nelson, A., Vandegrift, R., Carroll, G. C., and Roy, B. A. 2020. Double lives: Transfer of fungal endophytes from leaves to woody substrates. PeerJ 8:e9341.

Oksanen, J., Kindt, R., Legendre, P., O'Hara, B., and Stevens, M. H. H. 2007. The vegan package. Community ecology package. https://ftp.unibayreuth.de/math/statlib/R/CRAN/doc/packages/vegan.pdf

Ottesen, A. R., González Peña, A., White, J. R., Pettengill, J. B., Li, C., Allard, S., Rideout, S., Allard, M., Hill, T., Evans, P., Strain, E., Musser, S., Knight, R., and Brown, E. 2013. Baseline survey of the anatomical microbial ecology of an important food plant: Solanum lycopersicum (tomato). BMC Microbiol. 13:114.

Pandey, P. K., Singh, S., Singh, M. C., Singh, A. K., Yadav, S. K., Pandey, A. K., and Heisnam, P. 2018. Diversity, ecology, and conservation of fungal and bacterial endophytes. Pages 393-430 in: Microbial Resource Conservation. S. K. Sharma and A. Varma, eds. Springer International Publishing, New York, NY, U.S.A.

Peay, K. G., and Bruns, T. D. 2014. Spore dispersal of basidiomycete fungi at the landscape scale is driven by stochastic and deterministic processes and generates variability in plant-fungal interactions. New Phytol. 204:180-191.

Pent, M., Põldmaa, K., and Bahram, M. 2017. Bacterial communities in boreal forest mushrooms are shaped both by soil parameters and host identity. Front. Microbiol. 8:836.

Põlme, S., Abarenkov, K., Henrik Nilsson, R., Lindahl, B. D., Clemmensen, K. E., Kauserud, H., Nguyen, N., Kjøller, R., Bates, S. T., Baldrian, P., et al. 2020. FungalTraits: A user-friendly traits database of fungi and fungus-like stramenopiles. Fungal Divers. 105:1-16.

Purahong, W., Wubet, T., Lentendu, G., Hoppe, B., Jariyavidyanont, K., Arnstadt, T., Baber, K., Otto, P., Kellner, H., Hofrichter, M., and Bauhus, J. 2018. Determinants of deadwood-inhabiting fungal communities in temperate forests: Molecular evidence from a large scale deadwood decomposition experiment. Front. Microbiol. 9:2120.

Quast, C., Pruesse, E., Yilmaz, P., Gerken, J., Schweer, T., Yarza, P., Peplies, J., and Glöckner, F. O. 2012. The SILVA ribosomal RNA gene database project: Improved data processing and web-based tools. Nucleic Acids Res. 41:D590-D596.

Reischke, S., Rousk, J., and Bååth, E. 2014. The effects of glucose loading rates on bacterial and fungal growth in soil. Soil Biol. Biochem. 70:88-95.

Rodriguez, R. J., White, J. F., Arnold, A. E., and Redman, R. S. 2009. Fungal endophytes: Diversity and functional roles. New Phytol. 182:314-330.

Sharrow, S. H., and Ismail, S. 2004. Carbon and nitrogen storage in agroforests, tree plantations, and pastures in western Oregon, USA. Agrofor. Syst. 60:123-130.

Sun, X., Ding, Q., Hyde, K. D., and Guo, L. D. 2012. Community structure and preference of endophytic fungi of three woody plants in a mixed forest. Fungal Ecol. 5:624-632.

Tedersoo, L., Bahram, M., Põlme, S., Kõljalg, U., Yorou, N. S., Wijesundera, R., Ruiz, L. V., Vasco-Palacios, A. M., Thu, P. Q., Suija, A., et al. 2014. Global diversity and geography of soil fungi. Science 346 : 1256688 .

Tedersoo, L., Bahram, M., and Zobel, M. 2020. How mycorrhizal associations drive plant population and community biology. Science 367 : eaba1223.

Thomas, S. C., and Martin, A. R. 2012. Carbon content of tree tissues: A synthesis. Forests 3:332-352.

Unterseher, M., Petzold, A., and Schnittler, M. 2012. Xerotolerant foliar endophytic fungi of Populus euphratica from the Tarim River basin, Central China are conspecific to endophytic ITS phylotypes of Populus tremula from temperate Europe. Fungal Divers. 54:133-142.

Uroz, S., Oger, P., Tisserand, E., Cébron, A., Turpault, M. P., Buée, M., De Boer, W., Leveau, J. H., and Frey-Klett, P. 2016. Specific impacts of beech and Norway spruce on the structure and diversity of the rhizosphere and soil microbial communities. Sci. Rep. 6:27756.

Vacher, C., Hampe, A., Porté, A. J., Sauer, U., Compant, S., and Morris, C. E. 2016. The phyllosphere: Microbial jungle at the plant-climate interface. Annu. Rev. Ecol. Evol. Syst. 47:1-24.

Vandenkoornhuyse, P., Quaiser, A., Duhamel, M., Le Van, A., and Dufresne, A. 2015. The importance of the microbiome of the plant holobiont. New Phytol. 206:1196-1206.

van der Heijden, M. G. A., Bardgett, R. D., and van Straalen, N. M. 2008 The unseen majority: Soil microbes as drivers of plant diversity and productivity in terrestrial ecosystems. Ecol. Lett. 11:296-310.

van der Wal, A., Klein Gunnewiek, P. J. A., Cornelissen, J. H. C., Crowther, T. W., and de Boer, W. 2016. Patterns of natural fungal community assembly during initial decay of coniferous and broadleaf tree logs. Ecosphere 7:1-17.

Vannette, R., Hall, G., and Munkres, I. 2020. Fungi are more dispersallimited than bacteria among flowers. bioRxiv. 19.104968.

Yadeta, K. A., and Thomma, B. P. H. J. 2013. The xylem as battleground for plant hosts and vascular wilt pathogens. Front. Plant Sci. 4:97.

Zilber-Rosenberg, I., and Rosenberg, E. 2008. Role of microorganisms in the evolution of animals and plants: The hologenome theory of evolution. FEMS Microbiol. Rev. 32:723-735. 